Tropical Journal of Pharmaceutical Research February 2017; 16 (2): 463-470

ISSN: $1596-5996$ (print); 1596-9827 (electronic) (c) Pharmacotherapy Group, Faculty of Pharmacy, University of Benin,Benin City, 300001 Nigeria.

\title{
Practice of pharmaceutical care in community pharmacies in Jordan
}

\author{
Eman Elayeh ${ }^{1}$, Amal Akour ${ }^{1}$, Saba Almadaeen ${ }^{1}$, Tahani AlQhewii ${ }^{2}$ and Iman A \\ Basheti $^{3^{*}}$ \\ ${ }^{1}$ Department of Biopharmaceutics and Clinical Pharmacy, Faculty of Pharmacy, University of Jordan, Amman, Jordan 11942, \\ ${ }^{2}$ Royal Medical Services, Amman, 11821 Jordan, ${ }^{3}$ Faculty of Pharmacy, Applied Science Private University, Amman, 11942 \\ Jordan \\ *For correspondence:Email: dr_iman@asu.edu.jo Tel: +962 799048003 Fax: +962 65232899.
}

Received: 20 June 2016

Revised accepted: 1 September 2016

\begin{abstract}
Purpose: To describe the current role played by pharmacists in delivering pharmaceutical care (PC) in community pharmacies in Jordan (current activities and practices undertaken in the community and extent of provision of PC standards), pharmacists' perspectives on PC implementation and barriers to implementing PC practices.

Methods: This cross sectional study was conducted in 2014in Amman, the capital of Jordan and Zarqa, the second biggest city in Jordan. The study involved a validated questionnaire administered at random by trained pharmacy students to 180 community pharmacists. The questionnaire was designed to collect demographic data, pharmacy practice features displayed by the pharmacists, dispensing activities undertaken, internationally proposed PC practice standards in community pharmacy settings, inter/intra-professional and public heath activities and barriers that may hinder the implementation of PC practice in Jordan.

Results: 163 pharmacists agreed to participate in the study (response rate was $90.5 \%$ ). Most dispensing activities (98.1\%) in the pharmacies were done under the supervision of pharmacists. All pharmacists were willing to implement $P C$, and nearly all of them (98.8\%) provided basic information about medication use. Nevertheless, only $31.0 \%$ adapted standard procedures for patient's data collection, $23.1 \%$ formulated a therapeutic plan to be included within the patient's permanent record in their pharmacy, $24.2 \%$ documented over-the-counter recommendations, and $29.7 \%$ allocated time to discuss patient's care plans. Identified barriers preventing the provision of PC practice included lack of training on the concept (44.9\%) and lack of acceptability from the physicians (43.4\%).

Conclusion: Although participating pharmacists showed willingness to implement $P C$ practice, their actual application to the practice was found to be limited. Lack of adequate pharmaceutical training and acceptability by the physicians are the major barriers towards the provision of PC practice in the country.
\end{abstract}

Keywords: Community pharmacists, Pharmaceutical care, Barriers, Jordan

Tropical Journal of Pharmaceutical Research is indexedby Science Citation Index (SciSearch), Scopus, International Pharmaceutical Abstract, Chemical Abstracts, Embase, Index Copernicus, EBSCO, African Index Medicus, JournalSeek, Journal Citation Reports/Science Edition, Directory of Open Access Journals (DOAJ), African Journal Online, Bioline International, Open-J-Gate and Pharmacy Abstracts

\section{INTRODUCTION}

Pharmaceutical care $(\mathrm{PC})$ is defined as the direct, responsible provision of medicationrelated care for the purpose of achieving definite outcomes that improve a patient's quality of life [1].Throughout the last two decades, PC practice has been proven to lower healthcare costs, improve patients' quality of life and save lives of many patients [2-6]. In Jordan, the practice of PC 
was introduced over 10 years ago with the first step of establishing the Doctor of Pharmacy (PharmD) program. In addition, master degree in clinical pharmacy was introduced in 2004 in many universities in Jordan [7, 8].

Like many other countries, the community pharmacist in Jordan is trusted to have medical knowledge, and is considered easily accessible to patients. Hence, community pharmacists have become a favourable reference point in medical consultations and medications' inquiries since they give medical advice with no fees [9]. Therefore, they can be considered as the main contributors to PC practice. It is of interest to follow-up on their progress in establishing and delivering $\mathrm{PC}$ service and their impact in real practice.

In 2008, a survey was conducted at the community pharmacies in Jordan to study attitudes, knowledge and barriers facing community pharmacists in applying PC practice. The results were encouraging, as it showed that $90 \%$ of pharmacists were fully supportive of applying PC. Nevertheless, no more than $62 \%$ knew the basic concept of PC practice, and the actual practice of $\mathrm{PC}$ was scarce at that time [10]. Thereafter, many approaches were undertaken to enhance PC practice in the country since then. For example, courses of pharmacotherapy and pharmaceutical care were introduced to the Bachelor degree in pharmacy programme. Moreover, the Jordanian Pharmacist Association conducted courses in clinical pharmacy for the bachelor and master pharmacy students, and launched a comprehensive pharmacy practice project at the governmental level in 2008. Thereafter, hospitals were requested to apply the 'clinical pharmacy service' by the Ministry of Health [11].

The aim of this study was to investigate the current role of pharmacists in delivering pharmaceutical care in community pharmacies in Jordan, and to unveil barriers preventing them from fulfilling this role. This paper is expected to reveal the current understanding of the $P C$ practice concepts by community pharmacists in Jordan, implementation of such concepts by these pharmacists, and the obstacles facing this implementation.

\section{METHODS}

\section{Study design}

This study was conducted in Amman, the national capital of Jordan, and Zarqa, the second biggest city in Jordan. At the time of this study, there were 2057 community pharmacies in Jordan, out of which, 1308 (63.6 \%) were in Amman.

\section{Subjects and sampling procedure}

The study population involved community pharmacists in the capital of Jordan, Amman and in Zarqa City (the second biggest city in Jordan). For those who accepted to be included in the study, informed written consents were obtained. A selected group of $5^{\text {th }}$ and $6^{\text {th }}$ year pharmacy students from University of Jordan were trained to administer the questionnaire to 180 community pharmacies at random in Amman and Zarqa. Each student conducted the study at the community pharmacy where he/she was undergoing his/her undergraduate clinical training. A survey coordinator was selected to manage the logistic aspects of the survey, train students to administer the survey questionnaire, monitor data collection and track pharmacists' responses.

Pharmacists in the pharmacies were asked to fill a validated self-administered questionnaire.

\section{Instrument and Data collection}

The questionnaire was derived from a previously validated published study [12] to allow for an international comparison between prospective results. Questions were translated into lay Arabic language; translation was validated by two colleagues (clinical pharmacists) and then validated for content and clarity of language by distribution to twenty pharmacists, followed by the elimination or modification of unnecessary or ambiguous questions. The final form of the questionnaire consisted of five main areas: The first section addressed the demographic and practice characteristics of the pharmacists; second section addressed the dispensing activities undertaken which correlated with internationally published articles; third section addressed the internationally proposed PC practice standards in community pharmacy settings - in this section, the community pharmacists were asked to state whether any of the specified standards were already applied in their practice, then to indicate the extent to which they considered these standards appropriate for the future of community pharmacy practice in Jordan; the fourth section inter/intra-professional and public heath activities, using statements adapted from published literature - in this section the pharmacists were requested to report whether any of these activities were already applied and then to indicate their perceived importance; fifth section addressed the barriers 
that may hinder the implementation of $P C$ practice in Jordan.

In the third to the fifth sections, a 5-point Likert type scale was used to categorize the pharmacists' views. The questionnaire included open questions in addition to the closed questions. A covering letter explaining the study objectives was distributed with the questionnaire (in June 2013) by hand, addressed to the pharmacist in charge. Pharmacists were given a deadline of 3 days after which a survey coordinator would return to hand-collect their responses. To avoid coercion, it was made clear that pharmacists could drop out anonymously by returning blank questionnaire in the sealed envelope and that survey coordinator was not a member of the research team.

\section{Data analysis}

Data collected were analysed using Statistical Package for Social Sciences (SPSS for Windows, version 20 Chicago, IL, US). Chi square test was used to identify any significant difference among the participants' responses. At 95\% confidence interval, a 2-tailed $p$ values less than 0.05 were considered to be significant.

\section{RESULTS}

\section{Demographics}

Of the 180 questionnaires distributed, 163 were completed giving a response rate of $90.5 \%$. Respondents' characteristics are shown in Table 1.

\section{Activities currently undertaken in community pharmacies}

Dispensing and provision of basic information to customers, such as drug indications, dosage forms, counselling on adherence and side effects, and cost of drugs were the quintessence function of most pharmacists (Table 2). Most pharmacists $(98.1 \%, n=159)$ reported that dispensing was undertaken under their supervision. Most of these pharmacists (90.1\%, $\mathrm{n}=145$ ) reported providing oral patient counselling when dispensing each prescription (e.g. directions for use, indications, education on drug class, etc.) and also provided written instructions to patients on how to administer specialty products. Majority (87.7 \%, $\mathrm{n}=142)$ reported checking for the most economical therapeutic alternative for any medication and relaying the information back to the prescriber/ patient.
Table 1: Socio-demographic characteristics of pharmacists $(n=163)$.

\begin{tabular}{|c|c|}
\hline Variables & $\mathbf{N}(\%)$ \\
\hline \multicolumn{2}{|l|}{ Age groups } \\
\hline $20-30$ & $84(52.5)$ \\
\hline $31-40$ & $34(21.3)$ \\
\hline $41-50$ & $27(17.5)$ \\
\hline$>50$ & $14(8.8)$ \\
\hline \multicolumn{2}{|l|}{ Gender } \\
\hline Males & $71(45.2)$ \\
\hline Females & $86(54.8)$ \\
\hline \multicolumn{2}{|c|}{ Years of Pharmacy experience } \\
\hline$<1$ year & $12(7.6)$ \\
\hline $1-5$ years & $67(42.4)$ \\
\hline $6-10$ years & $19(12.0)$ \\
\hline $11-15$ years & $18(11.4)$ \\
\hline $16-20$ years & $20(12.7)$ \\
\hline$>20$ years & $22(13.9)$ \\
\hline \multicolumn{2}{|c|}{ Pharmacy qualifications } \\
\hline BPharm & $149(93.1)$ \\
\hline Master degree & $9(5.6)$ \\
\hline $\mathrm{PhD}$ & $1(0.6)$ \\
\hline Others & $1(0.6)$ \\
\hline \multicolumn{2}{|c|}{ Country of BPharm qualification } \\
\hline Jordan & $129(83.8)$ \\
\hline Outside Jordan & $25(16.2)$ \\
\hline \multicolumn{2}{|c|}{ Dispensing volume (prescriptions / day) } \\
\hline$<100$ & $31(22.0)$ \\
\hline $100-199$ & $37(26.2)$ \\
\hline $200-299$ & $29(20.6)$ \\
\hline $300-399$ & 15 (10.6) \\
\hline$>400$ & $29(20.6)$ \\
\hline
\end{tabular}

\section{Pharmaceutical care standards}

Regarding PC standards, a few PC activities were reported to be performed by the majority of participants. Examples include: maintaining a caring, friendly, and responsible relationship with the patients while taking a sincere interest in their health and drug therapy, asking questions (96.8 $\%, n=150)$, triaging the patient's OTC requests to determine if their problem requires referral, providing OTC treatment, or other supportive treatments such as vitamin and mineral supplements, providing non-pharmacologic interventions including but not limited to thermal therapy, diet, physical activities, and complementary therapy (96.1\%), exhibiting

Trop J Pharm Res, February 2017; 16(2): 465 
Table 2: Proportion of pharmacists reporting activities currently undertaken in the Jordanian pharmacies $(n=163)$

\begin{tabular}{|c|c|}
\hline Activities & N (\%) \\
\hline $\begin{array}{l}\text { Dispensing process is done by the } \\
\text { pharmacist or under his/her } \\
\text { supervision. }\end{array}$ & $159(98.1)$ \\
\hline $\begin{array}{l}\text { Pharmacists prepare extemporaneous } \\
\text { preparations }\end{array}$ & 118 (73.3) \\
\hline $\begin{array}{l}\text { Pharmacists keep a compounding log } \\
\text { for each batch of compounded product } \\
\text { prepared. }\end{array}$ & $61(38.4)$ \\
\hline $\begin{array}{l}\text { Pharmacists provide basic information } \\
\text { to customers on the use of medicines. }\end{array}$ & $161(98.8)$ \\
\hline $\begin{array}{l}\text { Pharmacists always apply labels to the } \\
\text { dispensed medicines. }\end{array}$ & 159 (98.1) \\
\hline $\begin{array}{l}\text { Pharmacists provide written } \\
\text { instructions to patients on how to } \\
\text { administer specialty products (i.e., ear } \\
\text { drops, ophthalmic drops and } \\
\text { ointments, rectal suppositories, } \\
\text { inhalers, injections, etc.) are given }\end{array}$ & $145(90.1)$ \\
\hline $\begin{array}{l}\text { Pharmacists provide oral patient } \\
\text { counselling with each prescription (e.g. } \\
\text { directions for use, indication, education } \\
\text { on drug classes, etc.) }\end{array}$ & 155 (95.1) \\
\hline $\begin{array}{l}\text { Pharmacists check for the most } \\
\text { economical therapeutic alternative for } \\
\text { any medication and relay this } \\
\text { information back to the } \\
\text { prescriber/patient. }\end{array}$ & $142(87.7)$ \\
\hline
\end{tabular}

knowledge concerning the impact of OTC drugs on outcomes of disease states by identifying appropriate use of OTC medications, their correct administration, their side effects, and knowledge of their interactions with diseases, prescription medications, vitamins and herbal supplements (e.g., the use of niacin in Type II diabetics) $(88.5 \%, n=139)$. Nevertheless, none of the pharmacists implemented the 28 standards at their pharmacies. Nineteen standards were implemented by more than $50 \%$ $(n=82)$ of pharmacists. When potential problems were identified, only 36 pharmacists $(23.1 \%)$ formulated a therapeutic plan to be included in the patient's permanent record. Documenting OTC recommendations on patient's profile was poor (24.2 \%, $\mathrm{n}=38)$. Not many pharmacists (29.7\%, n=46) gave sufficient time for patients who wish to make appointments to discuss their care/care plans, health or drug therapy. Devising a standard system of data collection of all necessary medical and personal information from each patient was very humble $(31 \%, n=49)$. This data collection forms include: prescribing physician(s), medication history, medical condition and diagnosis, allergies, and other data that would assist in detecting potential medical or treatment related problems.

\section{Community pharmacists' perspectives on PC implementation}

All pharmacists $(100 \%, n=163)$ were willing to implement PC, and more than $70 \%$ of them were positive about the appropriateness of the proposed PC standards implementation in Jordan to excel the future of pharmacy profession. There were two standards that pharmacists were less positive toward their implementation; allowing about 15 minutes via prearranged appointments with patients for those who wish to make appointments to discuss their care/care plans, health, or drug therapy with pharmacists $(47.5 \%, n=65)$, and documenting OTC recommendations on the patient's profile by pharmacists $(58.3 \%, n=74)$.

When pharmacists were asked about their perspectives regarding payment for PC services, $91 \%(n=142)$ agreed that delivering PC is complementary to attracting pharmacy's business, $76 \%(n=117)$ of pharmacists were willing to perform pharmaceutical care for free. Other perspectives are shown in Figure 1.

\section{Inter/intra-professional and public health activities}

Responses from the pharmacists on if any of the listed inter/intra-professional and public health activities were in place, and to point out how important these activities were for improving professional practice in Jordan are illustrated in Figure 2. Majority (> $80 \%$ ) considered these activities 'important' or 'very important'.

\section{Barriers to implementing pharmaceutical care practice}

The main barriers recognized to hinder the implementation of PC were pharmacist lack of pharmaceutical training $(44.9 \%, n=67)$, lack of acceptability by physicians $(43.4 \%, n=66)$, lack of supporting laws (42\%, $\mathrm{n}=63)$, pharmacists' lack of therapeutic knowledge and clinical problem solving skills $(39.4 \%, \mathrm{n}=61)$, and pharmacist lack of communication skills (38.2\%, $n=58)$.

\section{DISCUSSION}

Results of this study show that there is a positive perception and willing to implement PC standards by community pharmacists in Jordan as respondents support the concept of PC. More than $95 \%$ of pharmacists showed tendency 
toward building a professional relationship with their patients. Majority of pharmacists reported that they provide advice regarding the appropriateness of over-the-counter (OTC) medications and help patients with regards to self-medication and when referral to doctors is needed. More than $90 \%$ of them were active in providing general health information similar to previous studies [12]. However, respondents demonstrated poor documentation of OTC medication use, patient medical and social history, and potential treatment related problems. Only one third of the pharmacists adapted a standard system for patient data collection and less than quarter reported preparing a therapeutic plan to be included in the patient's permanent record in their pharmacies (sometimes done on paper or saved to the pharmacy database system, depending on the internal system followed at the pharmacy). Drug therapy monitoring was infrequent $(0.7 \%)$, so was the feedback to the patients' physicians regarding patients' treatment progress and outcomes $(5.8 \%)$. Conducting patient interviews to discuss individual care plans is still far from reality in Jordan, hindering an important element of PC practice. In conclusion the activities currently conducted by the pharmacists in Jordan are confined to mere dispensing activities, lacking documentation, and is not compliant with PC universal definition.

In the last decade, many approaches have been undertaken to improve and encourage PC understanding and implementation in Jordan. Courses of pharmacotherapy and pharmaceutical care have been introduced into the Bachelor degree in pharmacy program in various governmental and private Universities. In addition, master in clinical pharmacy was introduced into pharmacy practice in the curricula year of 2007/2008. Moreover, Doctor of Pharmacy program was also introduced in the year of 1999/2000 with the first class of graduates started their practice in 2006. At the governmental level, the Jordanian Pharmacists Association (JPA) initiated many courses of clinical pharmacy and launched a comprehensive pharmacy practice project in 2008 after which all hospitals were requested to establish the profession of clinical pharmacy in their institutions by the Ministry of Health. With such interventions, a better implementation of PC in the country was anticipated.

Traditional dispensing activities still prevail the community pharmacy practice in Jordan [10]. Nevertheless, there is a great improvement in the acceptance of PC implementation over years. Aburuzet et al [10] evaluated several aspects of
PC practice in Jordan, including attitudes towards PC by community pharmacists, knowledge of $P C$ practices, and barriers that hindered the practice of PC [10]. The study reported that almost all pharmacists (90\%) supported the concept of PC, and more than 62 $\%$ of them had a correct understanding of its concept. However, the level of reported PC activities conducted by the pharmacists at that time was limited, confined mainly to providing basic dispensing practice, such as advice on appropriate medicine use and side effects. The main reported barrier at that time was the need for more PC training. Generally, results from Jordan with regards to PC practice are more optimistic than those reported from other countries, such as Sudan [12], Thailand [13] and New Zealand [14].

Perceived barriers to the provision of PC changed over time (from 2008 as reported by Aburuz et al [10] to 2014 as reported by this study) as shown in Figure 3. Compared to 2008, many of the perceived barriers towards the provision of PC practices decreased. The main barrier, lack of training, was perceived by about $80 \%$ of the pharmacists in Aburuzet al study [10], while in this study the percentage was reduced to about $45 \%$. Yet, since that the major barrier to the provision of PC practice in Jordan remains the lack of adequate training, a wellstructured educational/training program is recommended for all community pharmacists. This training should focus on the importance of data collection of patients' medical and personal history including their prescription and OTC medications; it should also emphasize on the importance of allocating specific time to discuss patients' medications and health care plans.

Lack of time and lack of money were important barriers reported by pharmacists in Jordan and other third world countries such as Sudan [12]. This was not the case however in European countries $[15,16]$.

Physicians have a role in the successful implementation of PC in the community. As reported by $43.4 \%$ of respondents, physicians are current reluctant to modify patient prescriptions following pharmacists' recommenddations, even when the recommendations are evidence-based and of major concern. This problem can be resolved by the implementation of interprofessional workshops focussing on the roles of the different health care providers with regards to pharmaceutical care activities. Future studies should aim to assess the effect of such training, not only on health care providers' 
attitudes toward pharmaceutical care practices, but also on the implementation of such practices

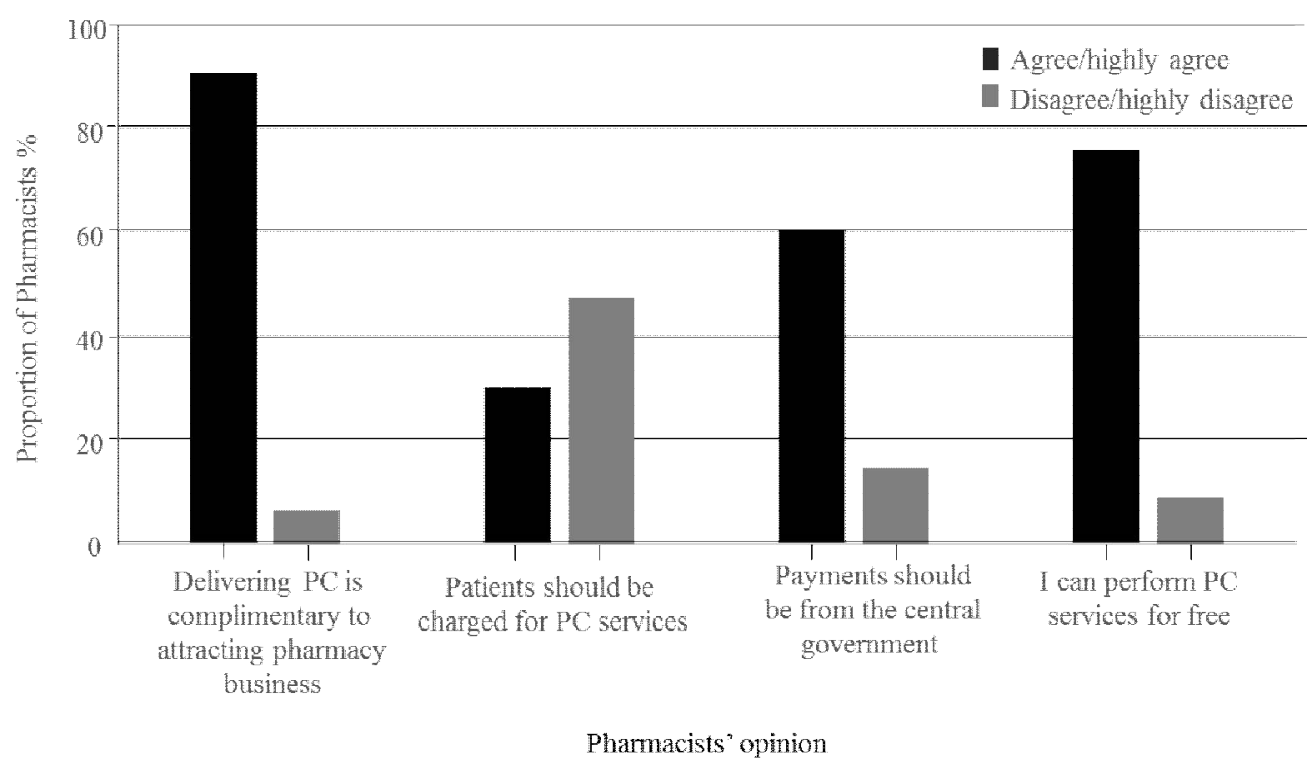

Figure 1: Pharmacists' opinion regarding payments for delivering Pharmaceutical Care services

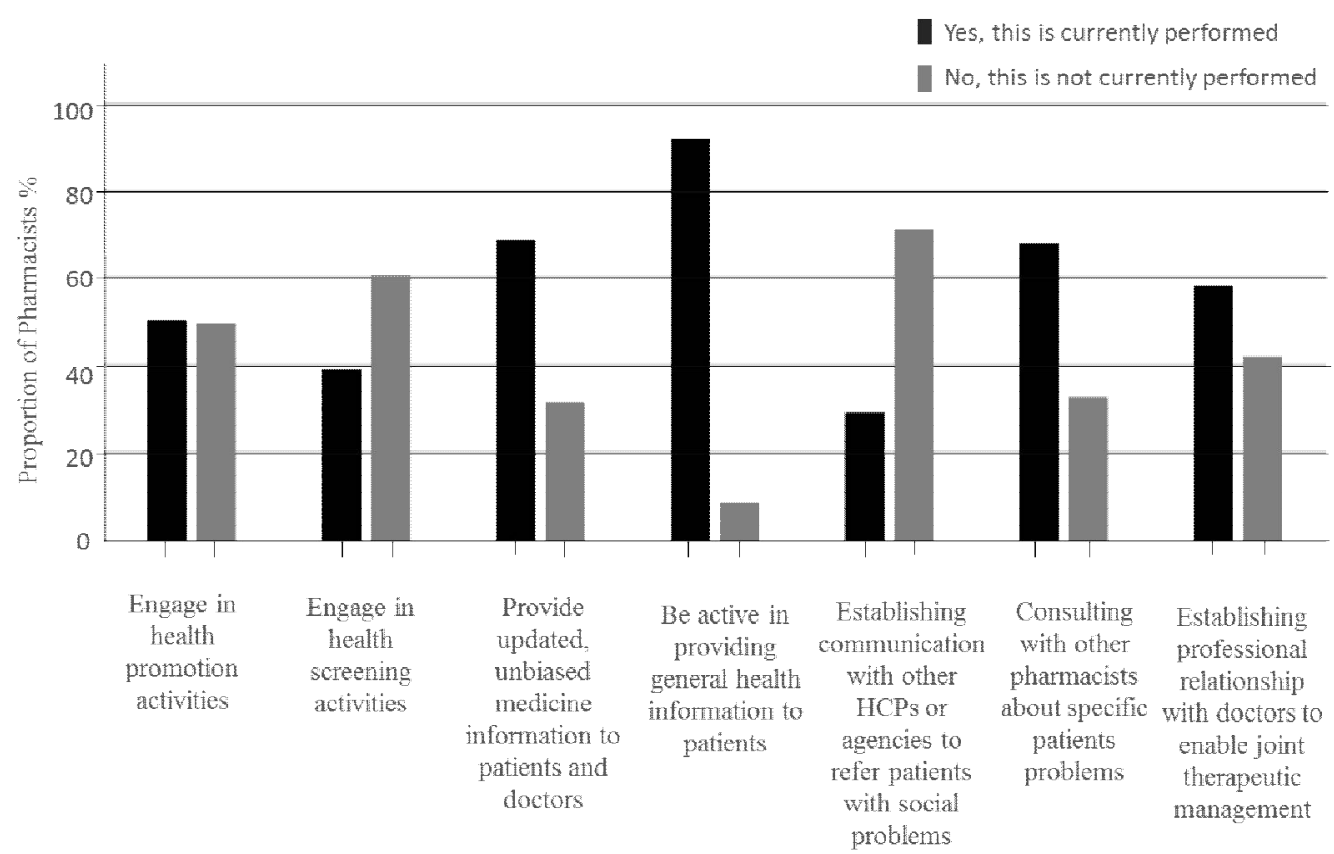

Pharmacists' opinion

Figure2: Pharmacists' perceived provision of inter/intra professional and public health activities

in the community and the eventual patient health outcomes.

Limitations of this cross-sectional study primarily lies in the small sample size and conventional sample technique followed probably leading to a biased sample. Thus, generalization of results from this study to community pharmacies in other cities in Jordan is difficult. This study was a mere longitudinal observation of the changes in pharmaceutical care perspectives over the last 6 years in Jordan. The study is liable to social desirability bias, as the responses were selfreported by study pharmacists.

\section{CONCLUSION}

This cross sectional study showed that community pharmacists in Jordan have improved attitude towards the implementation of PC practice in Jordan compared to 8 years ago. However, the actual application of PC to the 
practice is still limited. Lack of adequate pharmaceutical training and acceptability by

physicians remain to be the major barriers

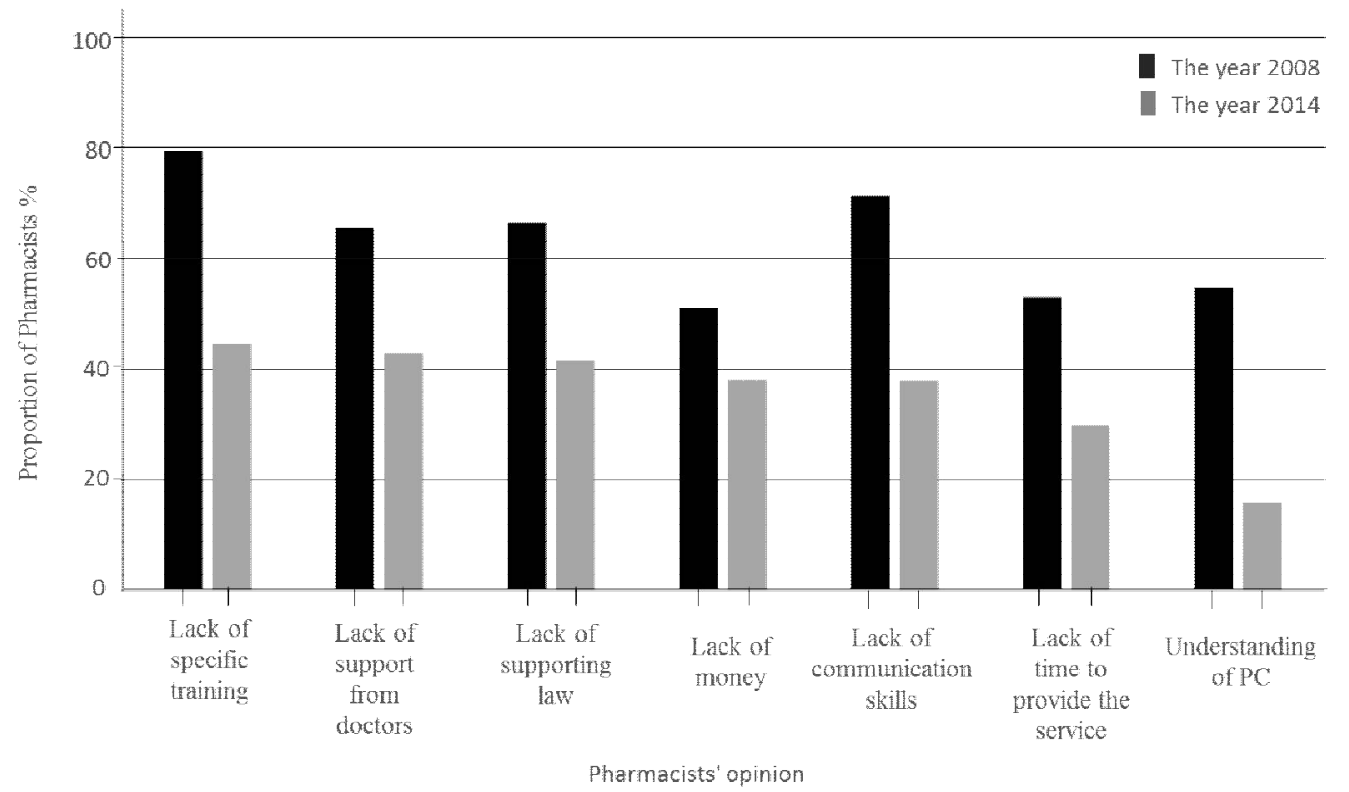

Figure 3: Barriers to implementing pharmaceutical care practice in Jordan in the year 2008 (as reported by Aburuzet al study [10]) vs. 2014 (current study)

towards the provision of PC practice in the country. Interprofessional training workshops are needed to encourage all health care professional to collaborate towards the provision of this important health care practice.

\section{DECLARATIONS}

\section{Acknowledgement}

We are grateful to the community pharmacists who participated in this work. We acknowledge the help of the pharmacist Mohamad Ghabayn.

\section{Funding}

The authors are grateful to the Applied Science Private University Amman, Jordan, for the partial financial support granted to this research project (Grant Number DRGS-2014-2015-205).

\section{Conflict of Interest}

No conflict of interest associated with this work.

\section{Contribution of Authors}

The authors declare that this work was done by the authors named in this article and all liabilities pertaining to claims relating to the content of this article will be borne by them. Eman Elayeh and Saba Almadaeen designed the study and collected the data, Eman Elayeh and Amal Akour did the literature search, Eman Elayeh, Iman
Basheti carried out the analysis of data, Eman Elayeh, Iman Basheti and Tahani AlQhewii prepared the manuscript and all authors read and approved it.

\section{Open Access}

This is an Open Access article that uses a funding model which does not charge readers or their institutions for access and distributed under the terms of the Creative Commons Attribution License (http://creativecommons.org/licenses/by/ 4.0) and the Budapest Open Access Initiative (http://www.budapestopenaccessinitiative.org/rea d), which permit unrestricted use, distribution, and reproduction in any medium, provided the original work is properly credited.

\section{REFERENCES}

1. American Society of Health-System Pharmacists'. Guidelines on a Standardized Method for Pharmaceutical Care. Am J Health Syst Pharm. 1996; 53 (14): 1713-1716.

2. Lagnaoui R, Moore N, Fach J, Longy-Boursier M, Begaud $B$. Adverse drug reactions in a department of systemic diseases-oriented internal medicine: prevalence, incidence, direct costs and avoidability. Eur J Clin Pharmacol. 2000; 56(2): 181-6.

3. Winterstein AG, Sauer BC, Hepler CD, Poole $C$. Preventable drug-related hospital admissions. Ann Pharmacother. 2002; 36(7-8): 1238-1248.

4. Lazarou J, Pomeranz BH, Corey PN. Incidence of adverse drug reactions in hospitalized patients: a meta-analysis of prospective studies. JAMA. 1998; 279(15):1200-1205. 
5. Bond CA, Raehl CL, Franke T. Clinical pharmacy services and hospital mortality rates. Pharmacotherapy. 1999; 19(5): 556-64.

6. Westerlund T, Marklund B. Assessment of the clinical and economic outcomes of pharmacy interventions in drug-related problems. J Clin Pharm Ther. 2009; 34(3): 319-327.

7. Al-Wazaify M, Albsoul-Younes A. Pharmacy in Jordan. Am J Health Syst Pharm. 2005; 62(23): 2548-2551.

8. Ayob M AS, Badran L, Al.Nsour W, Tahnh L. Committee of Clinical Pharmacy Job description. Clinical Pharmacist Job description: A Report of Ministry of Health, Amman, Jordan: Ministry of health. 2005.

9. Wazaify $M, A l-B s o u l-Y o u n e s ~ A, ~ A b u$-Gharbieh $E$, Tahaineh $L$. Societal perspectives on the role of community pharmacists and over-the-counter drugs in Jordan. Pharm World Sci. 2008; 30(6): 884-891.

10. Aburuz S, Al-Ghazawi M, Snyder A. Pharmaceutical care in a community-based practice setting in Jordan: where are we now with our attitudes and perceived barriers? Int J Pharm Pract. 2012; 20(2): 71-79.

11. Jordan Pharmaceutical Association. http://www.jpa.org. jo/index.php/cms/gpp. Amman, Jordan [Accessed 2016 February].
12. Ibrahim A, Scott J. Community pharmacists in Khartoum State, Sudan: their current roles and perspectives on pharmaceutical care implementation. Int $\mathrm{J}$ Clin Pharm. 2013; 35(2): 236-243.

13. Ngorsuraches S, Li SC. Thai pharmacists' understanding, attitudes, and perceived barriers related to providing pharmaceutical care. Am J Health Syst Pharm. 2006; 63(21): 2144-2150.

14. Dunlop JA, Shaw JP. Community pharmacists' perspectives on pharmaceutical care implementation in New Zealand. Pharm World Sci. 2002; 24(6): 224230.

15. Uema SA, Vega Em Fau - Armando PD, Armando Pd Fau - Fontana $D$, Fontana $D$. Barriers to pharmaceutical care in Argentina. Pharm World Sci. 2008; 30(3): 211-215

16. van Mil JW, Schulz M Fau - Tromp TFJD, Tromp TF. Pharmaceutical care, European developments in concepts, implementation, teaching, and research: a review. Pharm World Sci. 2004 Dec; 26(6): 303-11

17. Foppe van Mil JW, Westerlund T, Brown L, Chen TF, Henman M, Hersberger $K$, et al. Medical care and drug-related problems: Do doctors and pharmacists speak the same language? Int J Clin Pharm. 2016. [Epub ahead of print]. 